Avrupa Bilim ve Teknoloji Dergisi

Özel Sayı, S. 361-366, Ekim 2019

(C) Telif hakkı EJOSAT'a aittir

Arastırma Makalesi

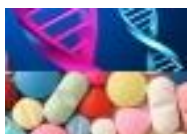

www.ejosat.com ISSN:2148-2683
European Journal of Science and Technology

Special Issue, pp. 361-366, October 2019

Copyright (C) 2019 EJOSAT

Research Article

\title{
Düşme Algılama Sistemi Tasarımı
}

\author{
Mehmet Yüksekkaya $^{1 *}$, Berna Yayla ${ }^{2}$, Muhammed Mehdi Menteş $^{3}$, Orhan Erdem Haberal ${ }^{4}$ \\ ${ }^{1}$ Biomedical Engineering Department, Baskent University, Ankara, Turkey(ORCID: 0000-0002-2665-5799) \\ ${ }^{2}$ Biomedical Engineering Department, Baskent University, Ankara, Turkey(ORCID: 0000-0001-7267-6550) \\ ${ }^{3}$ Biomedical Engineering Department, Baskent University, Ankara, Turkey(ORCID: 0000-0001-6365-7227) \\ ${ }^{4}$ Biomedical Engineering Department, Baskent University, Ankara, Turkey(ORCID: 0000-0003-2788-550X)
}

(Bu yayın "International Congress on Human-Computer Interaction, Optimization and Robotic Applications (HORA) July 5-7, 2019, Urgup, Nevsehir, Turkey” kongresinde sözlü olarak sunulmuştur.)

(İlk Geliş Tarihi 01.08.2019 ve Kabul Tarihi 25.10.2019)

(DOI: $10.31590 /$ ejosat.638320)

ATIF/REFERENCE: Yüksekkaya, M., Yayla B., Menteş M. M., \& Haberal E. H. (2019). Düşme Algılama Sistemi Tasarımı. Avrupa Bilim ve Teknoloji Dergisi, (Özel Sayı), 361-366.

\section{$\ddot{O} \mathbf{z}$}

Düşmeler beklenmedik olaylardır ve yaralanma, yaralanmayla ilişkili bozukluklar ve ölüm gibi ciddi sonuçlara yol açabilir. Düşme sonucunda kişi bilincini kaybedebilir ya da yardım çağıramayacak duruma gelebilir. Bu nedenle özellikle yaşlı nüfusun karşılaştığı en büyük sorunlardan birisi düşmedir. Yaşı kişiler düşme sonrası yardım çağıramama durumuna gelebilmektedir. Düşen kişiye kısa sürede müdahale, komplikasyonların oluşmasını engelleyebilir ve hayat kurtartabilir.

Bu projede düşme sonrası hareketsizliği algılayabilecek ve acil hizmetlere kablosuz uyarı gönderebilecek, pratik, küçük ve uygun maliyetli bir sistem tasarlanmıştır. Tasarlanan bu sistem düşme algılayıcı ve kablosuz uyarı uygulamasından oluşmaktadır. Düşme algılayıcı ivmeölçer, kablosuz veri aktarma modülü ve bunların kontrolü için mikrodenetleyiciden oluşmaktadır.

İvmeölçer sayesinde açısal konuma göre yerçekimi ivmesi belirlenmekte, ivme algılayıcısından gelen veriler çeşitli yazılım filtrelerinden geçtikten sonra deneysel olarak elde edilen farklı düşme tiplerinden oluşan karşılaştırma tablosu ile kıyaslanmakta ve daha sonra hareketin düşme olup olmadığına karar verilmektedir. Düşme algılandıysa kablosuz veri kablosuzu internet sistemi üzerinden iletilmektedir.

Düşme algılama sistemi 120 deneme sonucunda \%90 oranında düşmeyi algılamıştır, günlük kullanımda 2 gün boyunca düşme olmadığı durumda hiç hatalı düşme sonucu üretmemiştir. Tasarım 110 TL (20 USD)'ye mal olmuştur. Saat şeklindedir. $5 \times 4.5 \times 1.5 \mathrm{~cm}^{3}$ boyutlarında ve yaklaşık $50 \mathrm{~g}$ ağırlı̆̆ındadır.

Anahtar Kelimeler: Yaşlılık, Yaşlılarda düşme, İvmeölçer, Kablosuz veri iletişimi.

\section{Design of a Fall Detection System}

\begin{abstract}
Falls are unexpected events and can have serious consequences such as injury, injury-related disorders and death. As a result of falling, the person may lose consciousness or become unable to call for help. Therefore, one of the biggest problems especially for the elderly population is falling. Elderly people may be unable to call for help after falling.
\end{abstract}

\footnotetext{
* Sorumlu Yazar: Başkent Universitesi, Biyomedikal Mühendisliği Bölümü, Ankara, Turkey, ORCID: 0000-0002-2665-5799, mehmety@baskent.edu.tr
} 
In this project, a practical, small and cost effective system has been designed to detect post-fall immobility and send wireless alerts to emergency services. This system consists of a fall detector and wireless warning application. The drop sensor consists of an accelerometer, a wireless data transfer module and a microcontroller for their control.

The accelerometer measures the gravitational acceleration according to the angular position. Data from the accelerometer is passed through software filters and compared with the comparison table consisting of experimentally obtained fall types and then it is decided whether the motion is a fall or not. If a fall is detected, data is transmitted wirelessly over the internet system. The fall detection system detected $90 \%$ of falls over 120 trials and did not produce any false fall result if there was no fall in daily use for 2 days. The design cost $110 \mathrm{TL}$ (20 USD). It's packaged as a clock shaped. Its dimensions are $5 \mathrm{~cm} \times 4.5 \mathrm{~cm} \times 1.5 \mathrm{~cm}$ and weighs about $50 \mathrm{~g}$.

Keywords: Elders, Fall in the elderly, Accelerometer, Wireless data communication.

\section{Giriş}

İnsan yaşamındaki kronolojik dönemler, kişilerin sağlık durumlarını ve sağlık sorunlarını belirlemektedir. Yaşam boyunca farklı sağlık sorunlarıyla karşı karşıya kalınabilmektedir. Günümüzde yaşlı nüfusu giderek artmaktadır. Ülkemizde 2018 yılında nüfusun \% 8,2 kadarı yaşlıyken 2080 yılında nüfusun \% 26,6 kadarının yaşlı olması beklenilmektedir (Türkiye İstatistik kurumu Genel Sayım Sonuçları 2018-2020). Yaşam boyunca değiş̧ik sağlık sorunlarıyla karşı karşıya kalınabilmektedir. Yaşın büyümesiyle birlikte kişilerde bazı fizyolojik ve anatomik değişiklikler meydana gelmekte ve bu durum belirli yaşlardaki kişilerin bazı sağlık sorunlarına karşı daha duyarlı olmalarına neden olmaktadır (Barker 1998).

Yaşlılıktaki sağlık sorunları daha çok kronik ve dejeneratif hastalıklardır. Fiziksel yetersizlikler, ağrılar, kanser, kardiyovasküler hastalıklar, bilişsel bozukluklar, azalmış yaşam beklentisi ve sosyal izolasyon gibi sorunlar her ne kadar yaşlılara özel sağlık sorunları olmasalar da yaşlılıkta sık görülen sağlık sorunları arasında yer almaktadır (Bilir 1995 \& Abrams 1995). Yaşlılar sağlık sorunlarının daha az farkına varmaktadırlar ayrıca, semptomları inkar etme ya da şikayetlerini ifade etme güçlüğü, sağlık personelince yeterli ilgi gösterilmemesi, yakınmaların olağan sayılması ve sağılı hizmetlerine ulaşmada yaşadıkları sorunlar, gençlere göre öğrenim düzeylerinin düşük olması yaşlılıktaki sağlık sorunlarının yükünü artırmaktadır(Bilir 1995 \& Birtane 2000).

Yaşlılarda görülen bu sağlık sorunları karşısında düşmeler meydana gelmekte ve bu düşmeler ciddi sağlık sorunları oluşturmaktadır. Yaşlıların düşmesi sonucu oluşabilecek komplikasyonlara daha hızlı müdahale edilmesi sonucunda oluşacak ciddi sorunlara erken müdahale ederek oluşacak kalıcı sorunları erken tedavi ile daha aza indirgenebilir.

Bu çalışmada; düşmelerin daha çok hangi yaş gruplarında olduğu araştırılmıştır. Yaşlıların daha çok düştüğü ve aynı zamanda daha çok hasar aldığı belirlenmiştir. Yaşlıların düşme nedenleri araştırılıp oluşacak komplikasyonlar ortaya koyulmuştur. Kişilerde düşme sonucu oluşan komplikasyonlara erken müdahale edilmesi için düşmeyi algılayan ve düşme sonucunu ilgili kişi veya kurumlara iletebilen bir düşme algılama sistemi tasarlanmıştır. Bu sistem kişiye en kısa sürede müdahale edilmesini sağlayabilir.

\section{Materyal ve Metot}

\subsection{Tasarım}

Düşme algılama sistemi konum değişimini algılayabilen bir ivmeölçer, kablosuz internet verisi aktarımını sağlayabilen ve aynı zamanda tüm sistemin kontrolünü sağlayabilecek bir mikro denetleyici, pil ve şarj devresinden oluşmaktadır.
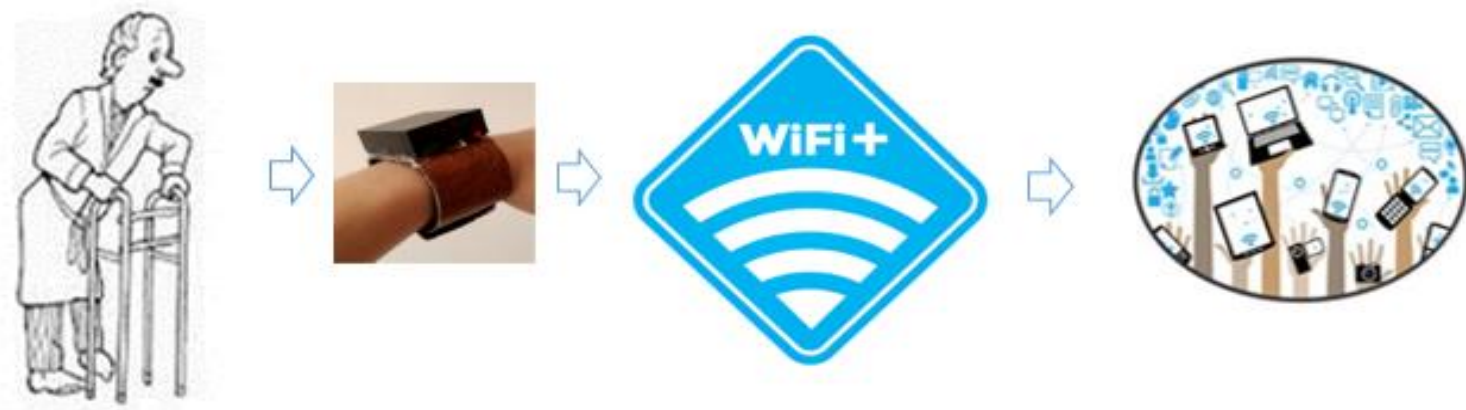

Şekil 1. Düş̧me Algılama Bileşenleri (sağdan sola kişsi, saat şeklindeki düşme algllama sistemi, verinin kablosuz internet veri iletiş̧imi ile iletilmesi ve ilgili kurumların ve kişilerin düşmeden haberdar olabilmeleri)

Sistem saat şeklinde olup, sensörler aracıllğıyla hareket algılayan, tasarlayan algoritmaya göre veriyi değerlendiren, kablosuz veri paylaşımı sağlayan, içerisindeki pil devresi sayesinde şarj gerektirmeyen ve acil durumlarda çağrı listesindeki kişilere acil durum uyarısı gönderebilen şekilde tasarlanmıştır. Sistem bileşenleri sekil 3'de verilmiştir.

Proje tasarımında öngörülen özelliklerin başında tasarımın, küçük, taşınabilir ve kablosuz veri aktarımını destekler nitelikte olması gerektiğine karar verilmiştir. Artık evlerde günümüzde kablosuz internet iletişimi mevcut olduğu için bu iletişim protokolünün 
kullanmaya karar verilip, aletin kolayca taşınabilir şekilde yapabilmesi için piyasadaki küçük cihazları araştırı tasarıma uygun olan WeMos kablusuz internet veri iletişimini destekleyen mikrodentleyici ve ADXL345 ivmeölçer' e karar verilmiştir.

\subsection{Malzemeler}

Tasarım yapılırken malzeme seçimleri gerçekçi kısıtlar/koşullar (çevre sorunları, sürdürülebilirlik, üretilebilirdik, etik, sağlık, güvenlik sosyal ve politik sorunlar) dikkate alınarak planlanmıştr. Aynı zamanda küçük, hafif ve maliyetin düşük olmasına önem verilmiştir. Bu sebeple yapılan piyasa araştırması sonucunda düşme algılama modülünde temel olarak bir kablosuz internet veri iletişimin destekleyen mikrodenetleyiciye, bir ivmeölçere, bir pil ve bu pil için şarj devresine karar verilmiş̧tir.

\subsubsection{Kontrol ve Kablosuz, Veri İletim Modülü}

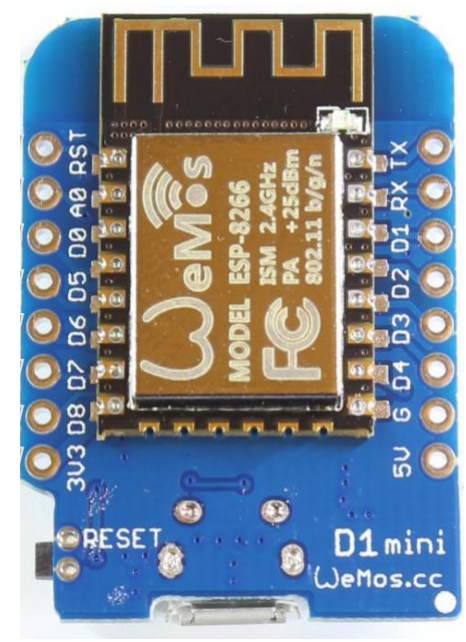

\section{Şekil 2. Kullanılan kontrol ve kablosuz veri iletim modülü}

Kontrol ve kablosuz veri iletim modülü olarak Arduino derleyicilere uygun olan Wemos ESP-8266 kullanılmasına karar verilmiştir. Kullanılan kontrol ve kablosuz veri iletim modülü madeni paradan biraz daha büyük boyutta, minik bir elektronik devredir. Açık kaynaktır, ucuzdur ve bu uygulama için yeterlidir. Düşük gerilimli enerjiyle çalışır. Üzerinde çok sayıda bağlantı noktaları vardır. Barındırdığı kablosuz veri iletimi sayesinde kolayca internet şeyleri (IOT) olarak bilinen cihazlarla kullanımı mümkündür. Modül üzerinde internet sunucusu çalşstırılabilir. Bu sayede internet üzerinden bu cihazla iletişime geçebilir veri toplanabilir ve uzaktan bir kontrol yapılabilir. Boyutu 34,2mmx $25.6 \mathrm{~mm}$, ağırlığı $10 \mathrm{~g}$ 'dır. Projede ivmeölçerden zamana göre gelen, 3 eksendeki yer çekimi ivmesi bilgisini alır, üzerinde çalıştırılan algoritma ile bu bilgiden düşme durumunu algılar ve sonucu kablosuzu internet veri iletişimi ile bir internet sayfasina aktarır.

\subsection{2. İvmeölçer}

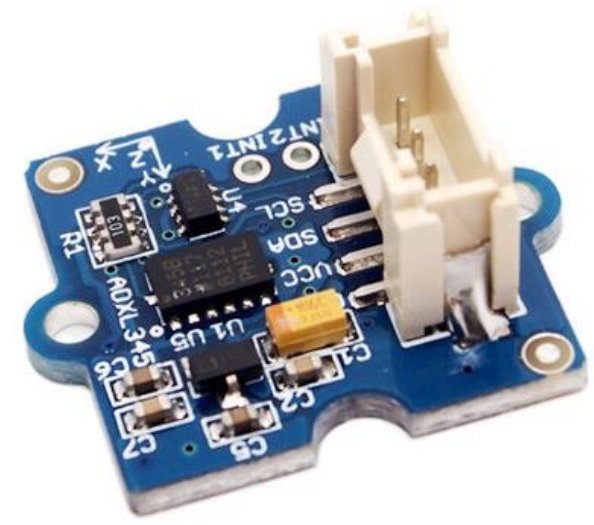

Şekil 3. Ivmeölçer

İvmeölçer olarak ADXL345 mikro çipini kullanan ve bu ivmeölçere göre hazırlanmış devresi olan bir tasarıma karar verilmiştir. İvmeölçerler aynı zamanda jiroskop olarak da adlandırılırlar. Jiroskop(gyrolar); yön ölçümü veya ayarlamasında kullanılan, açısal dengenin korunması ilkesiyle çalışan bir cihazdır. Jiroskopik hareketin temeli fizik kurallarına ve açısal momentumun korunumu ilkesine dayalıdır. 
ADXL345 ivmeölçer I2C ve SPI veri iletişim protokollerini desteklemektedir. Üç eksenli bir ivmeölçerdir. Hassasiyet seviyesi bir bit'e 4mg dir. Düşme algılamak için oldukça hassastır. Tasarımda ivmeölçer 3 eksende ivme bilgisini mikrodeneytleyiciye gönderir.

\subsubsection{Pil ve Şarj Devresi}

a

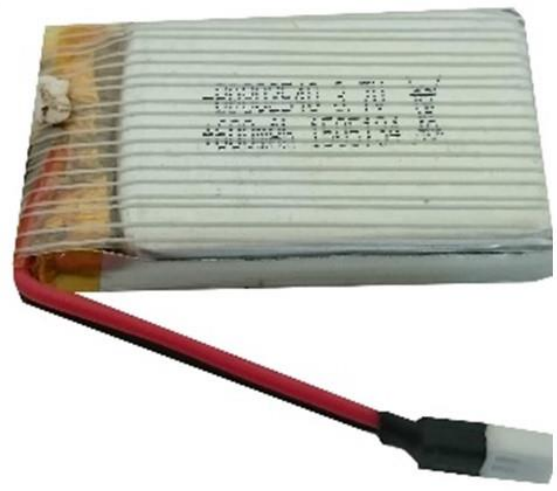

b

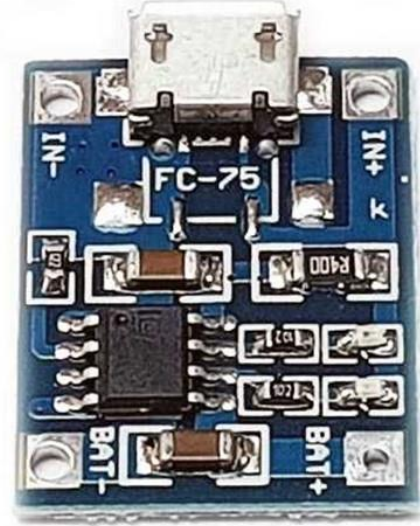

Şekil 4. a) şarj edilebilir pil ve b) pil şarj devresi

Şarj edilebilir pil olarak Lipo Pil - Lipo Batarya (Litium-ion)'ya karar verilmiştir. Kullanılan pil hücresi çok az dolu (\%5) iken 3V, tam dolu iken $4.2 \mathrm{~V}$ güç verebilir. Diğer pillere göre daha uzun ömürlü, daha hafif ve daha fazla deşarj kapasitesine sahiptirler. Hafif olması projelerde büyük avantaj sağlamaktadır. Düşme algılama sisteminde şarj edilmeden 3 güne kadar kullanılabilmektedir.

\subsection{Montaj}

Prototip tasarım, pil, şarj devresi, kontrol ve kablosuz veri iletim modülü, ivmeölçerin ve bunları çevreleyecek saat şeklinde kola takılabilen bir kutudan oluşmaktadır. Açma kapama düğmesi ve pil şarj için bağlantı ucuda eklenmiştir tasarım Şekil 5 te gösterilmiştir.

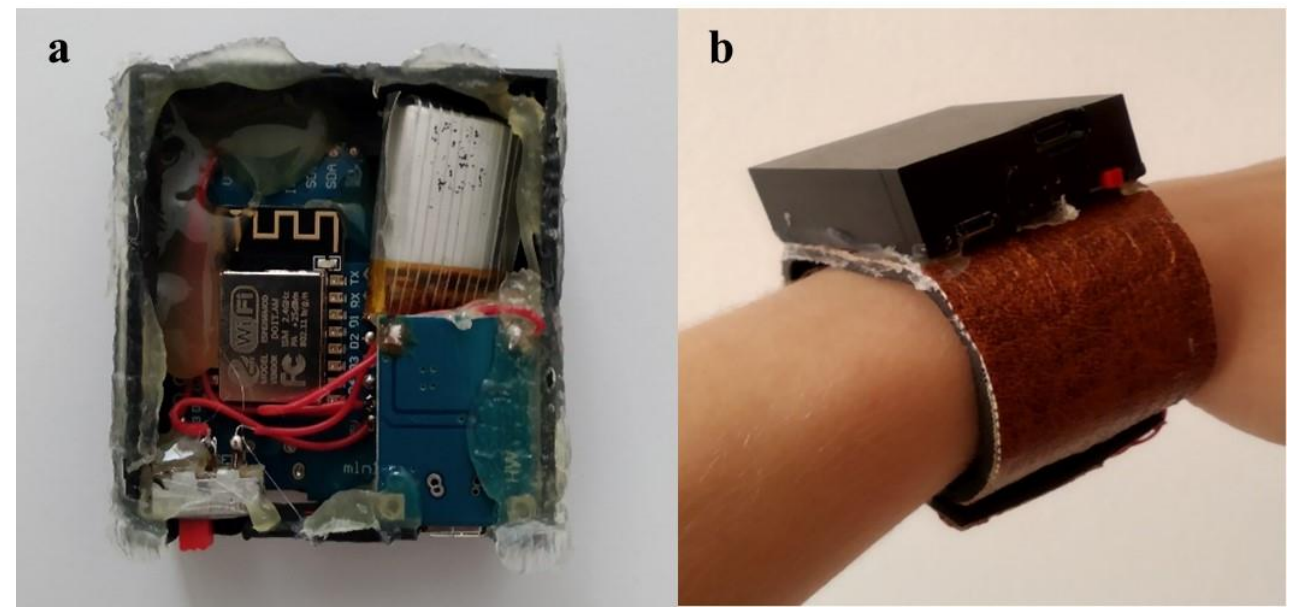

Şekil 5. a) Sistemin içyapısı b) Sistemin tamamı

\subsection{Düşme Algılama Yöntemi}

Kullanılan ivmeölçer, $\mathrm{x}$, y ve $\mathrm{z}$ eksenlerindeki ivme değerlerini I2C protokolü ile seri olarak iletmektedir. Okunan $\mathrm{x}, \mathrm{y}$ ve $\mathrm{z}$ eksinindeki ivme değerlerinden aşağıda belirtilen denklem sayesinde bir ivme vektörü boyu elde edilmiştir.

$$
A=\sqrt{x^{2}+y^{2}+z^{2}}
$$

Yapılan deneyler sonucunda düşme durumunda 1 saniye içinde ivme vektörünün boyundaki fark $2 \mathrm{G}$ değerinden büyük olmaktadır. Düşme algılamanın doğru olarak tanımlanması için yürüme, oturma, boşta durma ve cihazın düşmenin gerçekleştiği yönün aksi yönünde 2G' lik fark oluşacak şekilde hareket ettirilmesi gibi durumlarda düşmenin algılanmaması için gerekli çalışmalar incelenmiştir (M.L.M.G 2011). Şekil 6, da düşme ivme vektörünün boyundaki değişim zaman göre gösterilmektedir. Ve bu veri alınırken düşme durumu oluşmuştur.

\subsection{Algoritma}

Düşme algılama programı Arduino uyumlu ANSI-C dilinde yazılmıştır ve kontrol ve kablosuz internet iletişimi modülüne aktarılmıştır. Algoritması şekil 7'de temel hatlarıyla görülebilir. 
Düşme algılama sisteminde kontrol ve kablosuz internet iletişimi modülü üzerinde algoritma çalışır ve düşme oluşup oluşmadığını belirler ve bu veri ağda önceden belirlenmiş bir IP (internet protokolü) adresine düşme var ya da düşme yok şeklinde bilgiyi aktarır.

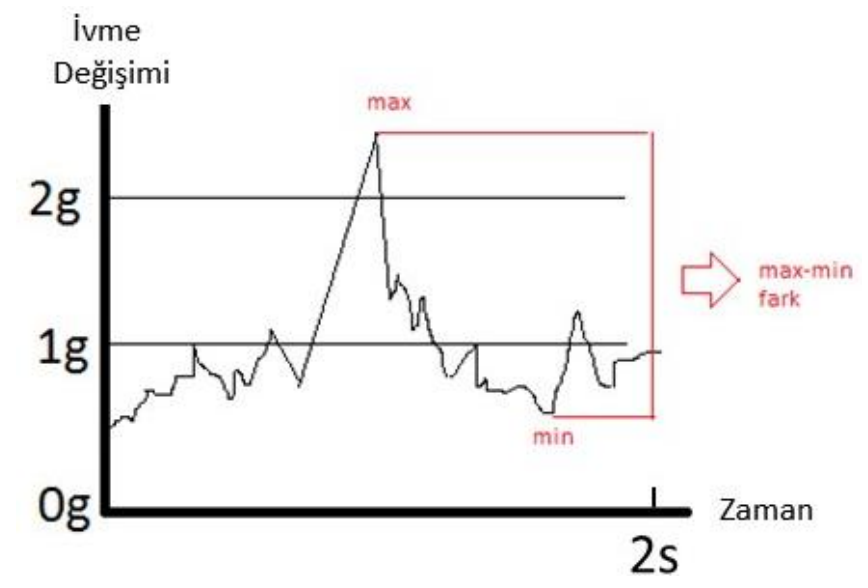

Şekil 6. Düşme oluşma durumu

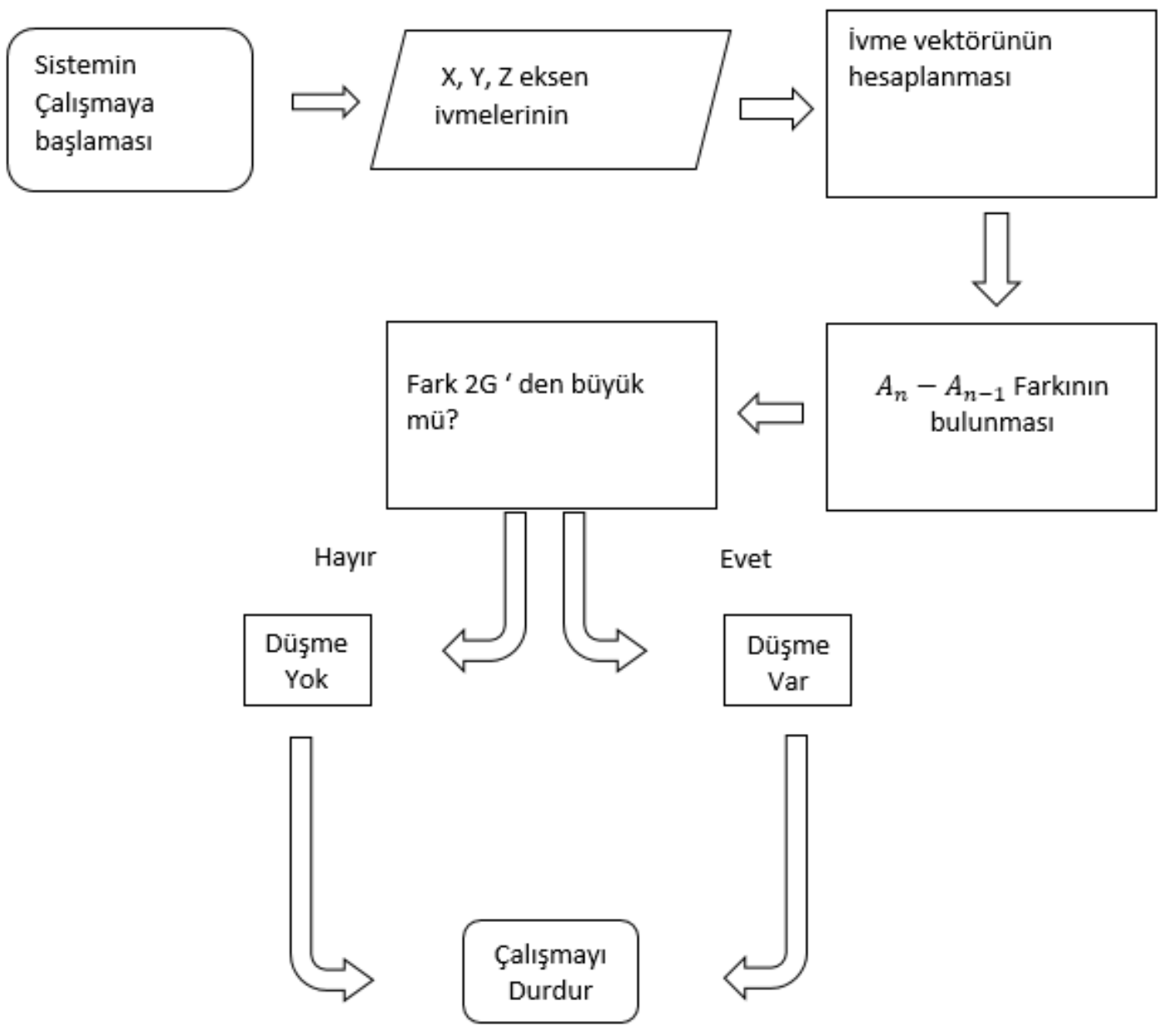

Şekil 7. Algoritma

Algoritmada ilk olarak bir IP adresi oluşturulur ve ivmeölçer çalışmaya başlar. İvmeölçer x, y, z eksenlerinden ivme değerlerini belirler ve alınan ivme değerleri işleme sokularak ivme vektörünün boyu elde edilir. Ardından bir saniye sonraki ivme vektörü ile önceki ivme vektörü arasındaki fark alınarak $2 \mathrm{G}$ den büyük olup olmadığ $10 \mathrm{~ms}$ sıklıkla kontrol edilir. Eğer $2 \mathrm{G}$ den küçük bir değer ise düşmenin olmadığı program tarafından IP adresine 5 saniyelik periyotlar ile bildiril. Elde edilen değer $2 \mathrm{G}$ den büyük olduğu takdirde ise 15 saniye boyunca hareket algılanmaması durumunda düşmenin var olduğu ve kişinin bilincini kaybettiği olay gerçekleştiği bilgisi IP adresine gönderilir ve program sonlanır. Eğer bu kıyaslama sonucu bir düşme ve sonrasında bilinç kaybetme olarak değerlendirilirse 
veri iletişim algoritmasına geçilecektir ve veri iletilecektir. Uygulama temel olarak düşme algılama sistemine internet üzerinden bağlandıktan sonra oradan gelen veriye göre daha önceden tanımlanmış çağrı listesinde bulunan kişilere, tanımlı çağrı mesajını herhangi bir acil durum olduğunda göndermektedir. Bu sayede hasta yakınları hızlı müdahalede bulunabileceklerdir.

\section{Testler}

Sistemin oluşturulması sonrasında yapılan testlerin sonucunda elde edilen verileri yazılım programı vasıtası ile grafik haline getirilmiş̧tir. Grafiklerde düşmenin algılandığı durum, yürüme grafiği, oturma grafiği ve boşta durma anları değerlendirilmiştir. Sistem testleri yapılırken kişi yumuşak zemine kolunda sistem takılı iken 120 defa düşme hareketi yapmıştır. Düşme öne doğru olmuştur ve her seferinde her iki kol koruma amaçlı öne açılmıştır. Bu durumda ivme vektörünün boyundaki değişim $2 \mathrm{G}$ den fazla olduğu için düşme algılanmıştır. Eğer kollar öne açılmadan düşme gerçekleştirildiğinde 120 denemeden sadece 8 tanesinde ivme vektörünün büyüklük farkı $2 \mathrm{G}$ den az olmuştur. Sistem $\% 90$ oranında düşmeyi algılamaktadır.

\section{Sonuç ve Öneriler}

Farklı pozisyonlarda düşme ve normal hareketin ayırt edilmesini sağlayan düşme algoritması mikro denetleyici tabanlı sistemlerde çalışabilecek şekilde tasarlanmıştır. Tasarlanan bu sistem algılayıcı modül ve geliştirilebilen internet uygulamasından oluşmaktadır.

Daha sonra tasarlanan sistem sonucunda elde edilen veri alınıp internete aktaran kod hazırlanmıştır. Buna bağlı olarak uygun denetleyici kodu yazılmıştır. Düşme algoritması oluşturulmuş ve oluşturulan bu algoritma sonucu elde edilen düşme sonuçları değerlendirilmiştir. Düşme algılama sistemi 120 deneme sonucunda $\% 90$ oranında düşmeyi algılamıştır, günlük kullanımda 2 gün boyunca düşme olmadığı durumda hiç hatalı düşme sonucu üretmemiştir.

Yapılan çalışmalar neticesinde başarı oranının yüksek olduğu ancak halen daha geliştirilebilir olduğu sonucu elde edilmiştir. Örneğin düşme durumu olmamasına karşın ani ve hızlı bir hareket sonucunda algoritma düşme algılayabilir fakat sonrasında 15 saniyelik bir durma durumu olmuyor bilinç kaybı olmadığı için uyarı sinyali gitmeyecektir.

Günümüzde sağlık politikalarında erken teşhis, erken müdahale, önleyici ve engelleyici tedbirlerle sağlık harcamalarının düşürülmesi sağlanmaya çalışılmaktadır. Geliştirilen bu sistem ile düşen kişilere erken müdahale edilmesi sağlanarak, sağlık giderlerindeki maliyetin azalması hedeflenmektedir. Şu an için geliştirilen prototip daha taşınabilir hale getirilebilir.

Kısacası sistem düşme algılama konusunda yenilikçi bir çözüm sunarken geliştirmeler ve eklemeler ile erken uyarı konusunda çok faydalı sonuçlar ortaya koyabilir.

\section{Kaynakça}

Türkiye İstatistik Kurumu Genel Sayım Sonuçları (2018-2080).

Barker WH, Prevention of disability in older persons, Wallace RB,Maxcy-Rosenau-Last Public Health \& Preventive Medicine, fourteenth edition, Appleton \& Lange, (1998)

Bilir N, Bulaşıcı olmayan hastalıkların kontrolü ve yaşl1lık sorunları, Bertan M, Güler Ç, Halk Sağlığı Temel Bilgiler, Güneß Kitabevi,Ankara (1995)

Abrams WB, Beers MH, Berkow R. "The Merck Manual of Geriat-rics", Second Edition, Merck \& Co., Inc. Whitehouse Station, N.J.USA (1995)

Birtane M, Tuna H, Ekuklu G, Uzunca K, Akçi C, Kokino S. Edir-ne huzurevi sakinlerinde yaşam kalitesine etki eden etmenlerin irdelenmesi. Turkish Journal of Geriatrics. (2000); 3: 141-145

M.L.M.G. Hristijan Gjoreski, "Accelerometer Placement for Posture Recognition and Fall Detection," in Seventh International Conference on Intelligent Environments (2011). 